\title{
Risk factors for primary open-angle glaucoma in Japanese subjects attending community health screenings
}

This article was published in the following Dove Press journal:

Clinical Ophthalmology

19 October 201 I

Number of times this article has been viewed

\author{
Makoto Ishikawa \\ Yu Sawada \\ Noriko Sato \\ Takeshi Yoshitomi \\ Department of Ophthalmology, \\ Akita Graduate University School \\ of Medicine, Akita, Japan
}

Correspondence: Makoto Ishikawa Department of Ophthalmology, Akita Graduate University School of Medicine, Hondo I-I-I,Akita 0 I0-8543, Japan

Tel +8I I8 834 I I I I ext 3472

$\mathrm{Fax}+8 \mid 188362621$

Email mako@med.akita-u.ac.jp
Background/aims: To describe risk factors associated with primary open-angle glaucoma (POAG) in Japanese subjects who participated in community health screenings.

Methods: Residents of Akita, Japan, participating in a community health checkup were selected to undergo a comprehensive ophthalmic examination. Glaucoma was diagnosed based on optic disk appearance, perimetric results, and other ocular findings. Systemic blood pressure and intraocular pressure were measured and ocular perfusion pressure was calculated. Logistic regression analysis was performed to determine risk factors for POAG patients.

Results and conclusion: Of the 710 subjects examined, 26 had POAG. The estimated prevalence of POAG was $3.7 \%$. After adjusting for age, the prevalence of POAG was similar to that found in the Tajimi Study of Japanese subjects. Multivariate logistic regression analysis demonstrated that older age ( $\geq 60$ years, odds ratio [OR]: 3.49 ), lower diastolic blood pressure ( $\leq 58 \mathrm{mmHg}$, OR: 2.11 ), higher intraocular pressure ( $\geq 19 \mathrm{mmHg}$, OR: 4.12), and lower ocular perfusion pressure ( $\leq 34 \mathrm{mmHg}$, OR: 5.78) were associated with increased risk of having POAG. These findings may be relevant for identifying high risk groups.

Keywords: glaucoma, community health screening, risk factors

\section{Introduction}

Glaucoma is the leading cause of blindness, and 22.5 million people worldwide are estimated to suffer from it. The Tajimi screening study estimated that the prevalence of primary open-angle glaucoma (POAG) in Japanese subjects older than 40 years was $3.9 \%$, of which $93.3 \%$ were previously undiagnosed. ${ }^{1}$ There is good evidence that age, family history, intraocular pressure (IOP), and African ancestry are risk factors for POAG. ${ }^{2-4}$ To better identify persons at risk for developing glaucoma, it is very important to determine what other risk factors for POAG also exist.

According to the vascular hypothesis of POAG pathogenesis, ${ }^{5}$ low blood pressure (BP) relative to IOP could lead to low ocular perfusion pressure (OPP), thus impairing perfusion of the optic nerve and causing glaucomatous loss of the visual field. In this context, vascular factors have been investigated with attention to BP and OPP. ${ }^{6-10}$ Recently, the population-based cohort study ${ }^{11,12}$ revealed that low systolic BP and low OPP were risk factors for POAG. However, there are only a few studies that have reported associations between POAG and BP-related factors in Japanese ${ }^{13}$ and other Asians. ${ }^{14,15}$

Recently, we conducted a community health checkup project in the city of Akita, located in northeastern Japan. The project involved glaucoma screening as well as general physical examinations. The purpose of this study was to identify the systemic and ocular risk factors associated with POAG in this population. 


\section{Subjects and methods}

This was a cross-sectional study in an institutional setting. Subjects older than 30 years were recruited at an annual community health checkup project held in the city of Akita (population 325,537), the capital of Akita Prefecture, Japan. A total of 1173 subjects participated in the comprehensive examinations from September 10, 2007 to October 26, 2007. Of these, 710 individuals underwent glaucoma screening. All of the participants were ethnically Japanese.

This study was performed after approval by the Ethics Committee of Akita Prefecture Health Care Foundation. All study procedures adhered to the principles outlined in the Declaration of Helsinki for research involving human subjects, and all participants gave written informed consent for this research prior to their participation.

\section{Screening examination}

The screening examination included the recording of systemic and ocular disorder history, height, weight, blood hemoglobin Alc $\left(\mathrm{HbA}_{1 \mathrm{c}}\right)$ status, alanine aminotransferase (ALT), serum cholesterol, and BPs. The initial noncontact ocular examination was conducted by trained non-ophthalmologists and included measurement of refraction and keratometry (KR-8100PA; Topcon, Tokyo, Japan), IOP by noncontact pneumotonometry (Topcon CT-90A), angle width (Scanning Peripheral Anterior Chamber Analyzer; Takagi Seiko, Nagano, Japan), non-mydriatic optic disk photography by stereoscopic fundus camera ( $30^{\circ}$ angle, 3 -DX/NM; Nidek, Gamagori, Japan), and confocal laser scanning tomography (Retina Tomograph II, software v 3.0; Heidelberg Instruments, Heidelberg, Germany). IOP was measured three times, and the mean value was used.

\section{Definitive examination}

A definitive examination was performed when a subject was suspected to have glaucoma based upon the findings of the initial noncontact ocular examination. The definitive examination consisted of the following procedures: slit-lamp biomicroscopy, Goldmann applanation tonometry, gonioscopy, and optic nerve head evaluation using a Goldmann three-mirror lens (Haag-Streit International, Koeniz, Switzerland) and a visual field test with the Humphrey Field Analyzer II 24-2 SITA Standard Program (Carl Zeiss Meditec Inc, Dublin, CA). Diagnosis of glaucoma was made based on optic disk appearance, including cup-to-disk ratio, rim width, nerve fiber layer defect, the visual field test, and the clinical records that were obtained through screening and definitive examinations. When present or suspected, glaucoma was categorized based upon the criteria of previous population studies (Table 1). ${ }^{1,16}$ In the definitive diagnosis, anomalous disks, including tilted disks, were carefully excluded.

\section{Assessment of risk factors}

The systemic variables of age, gender, body mass index (BMI), systolic (SBP) and diastolic blood pressure (DBP), diagnosis of hypertension, blood pressure-lowering treatment, diabetic status (glycated hemoglobin, $\mathrm{HbA}_{1 \mathrm{c}} \geq 5.8 \%$ and/or previous diagnosis as diabetes mellitus), ${ }^{17}$ liver dysfunction (ALT $\geq 40 \mathrm{IU}$ and/or previous diagnosis as liver dysfunction), and hypercholesterolemia were selected as possible risk factors. BMI was calculated as weight (kilograms) divided by the height (meters) squared. Blood pressure was measured after participants had been seated comfortably for at least 5 minutes. A single measure of SBP and DBP was used. Hypertension was defined using the 2003 World Health Organization guideline ${ }^{18}$ with $\mathrm{SBP} \geq 140 \mathrm{mmHg}$ or DBP $\geq 90 \mathrm{mmHg}$. Subjects who had a history of hypertension medication were also defined as having hypertension. Hypercholesterolemia was defined when cholesterol levels were greater than the upper limit of the normal range $(220 \mathrm{mg} / \mathrm{dL}) \cdot{ }^{19}$

Table I The criteria for primary open-angle glaucoma diagnosis

\section{Category I}

The vertical cup-to-disk ratio of the optic nerve head is 0.7 or more, or the rim width at the superior portion (II-I o'clock) or the inferior portion (5-7 o'clock) is 0.1 or less of the disk diameter, or the difference of the vertical cup-to-disk ratio is 0.2 or more between both eyes, or a nerve fiber layer defect is found, and the hemifield-based visual field abnormality is compatible with optic disk appearance or nerve fiber layer defect.

\section{Category 2}

When the visual field test is not reliable or available, the cup-to-disk ratio of the optic nerve head is 0.9 or more, or the rim width at the superior portion (I I-I o'clock) or the inferior portion (5-7 o'clock) is 0.05 or less of the disk diameter, or the difference of the vertical cup-to-disk ratio is 0.3 or more between both eyes.

\section{Glaucoma suspect}

When the cup-to-disk ratio of the optic nerve head is 0.7 or more but less than 0.9 , or the rim width at the superior portion (I I-I o'clock) or the inferior portion (5-7 o'clock) is 0.1 or less but more than 0.05 of the disk diameter, or the difference of the vertical cup-to-disk ratio is 0.2 or more but less than 0.3 between both eyes, or the nerve fiber defect is found, and the visual field test is not reliable or available or does not show hemifield-based compatible defect, the eye is diagnosed with suspected glaucoma. 
In addition, the ocular variables of IOP, OPP, and myopia were selected for study. Myopia was defined as myopic spherical equivalent (SE) $<-1.0$ diopter. If only one eye of the POAG patient was affected, the IOP, OPP, or SE was defined as the value of the glaucomatous eye. For control subjects and for bilateral POAG patients, the IOP was defined as the highest mean value in either eye. By contrast, OPP and SE were defined as the lowest value in either eye. The OPP was calculated as $2 / 3$ (mean arterial pressure) - IOP, where the mean arterial pressure $=\mathrm{DBP}+1 / 3(\mathrm{SBP}-\mathrm{DBP})$.

\section{Data analysis}

All of the participants' private information was kept in the protection of the Department of Ophthalmology, Akita Graduate University Faculty of Medicine. The data were double-checked and analyzed using the Statistical Package for the Biosciences (v 9.53; SPBS, Nankodo Publisher, Tokyo, Japan) on a personal computer. Systemic and ophthalmologic data of all participants diagnosed with definitive POAG were analyzed in the present study.

The prevalence of glaucoma and $95 \%$ confidence interval ( $95 \% \mathrm{CI}$ ) were calculated for each age group. To compare prevalence of POAG in our population with that in the Tajimi Study population, ${ }^{1}$ we determined the age-specific risk of POAG using a standardized mortality ratio (SMR). The SMR for POAG was the age-specific ratio between the observed number of POAG subjects in the study population and the expected number of POAG subjects calculated from the Tajimi study population. The age group of 30-39 years, including 42 normal persons and one POAG patient, was excluded from our analysis because the Tajimi Study did not include comparable data.

Continuous variables were recorded as means \pm standard deviations. For the assessment of risk factors, mean values were compared by Student's $t$-test and frequencies by the chi-square test. A control group was selected in this study population, and consisted of 634 participants who did not have glaucoma or suspected glaucoma, and who had no other ocular diseases including congenital disk anomalies that could affect the disk shape. ${ }^{3}$ We estimated the multivariateadjusted odds ratios (OR) and the $95 \% \mathrm{CI}$ for each potential risk factor by using logistic regression analysis. Explanatory variables included in the analyses were age, gender, BMI, SBP, DBP, hypertension, blood pressure-lowering treatment, diabetic status, liver dysfunction, hypercholesterolemia, IOP, OPP, and myopia. Continuous data such as age, DBP, IOP, and OPP were analyzed as categorical variables using quartile values based on the study population. These risk factors were adjusted for age, gender, blood pressure-lowering treatment, IOP, and OPP. For all analyses, $P$-values were two-sided and were considered statistically significant when the values were less than 0.05 .

\section{Results}

The average age of all 710 participants (384 male, 326 female) was $54.7 \pm 9.8$ years. Of the 710 participants examined in the initial screening, 163 (23.0\%) were referred for definitive examination, but 29 declined or were unable to participate. After definitive examination, 29 of the 134 participants were diagnosed with glaucoma, and 29 participants with suspected glaucoma. Previously undiagnosed glaucoma was present in 26 of the 29 subjects with glaucoma (89.6\%). Of the 29 patients with glaucoma, 26 had POAG. The other three had primary angle-closure glaucoma and were not included in this study. The prevalence of all glaucoma in each age group was shown in Table 2. The prevalence of POAG was $3.7 \%$ (95\% CI: $2.8 \%-5.5 \%$ ), and 24 were diagnosed with Category 1 disease and two with Category 2 disease. In $96.2 \%$ of glaucoma patients, the IOP was $21 \mathrm{mmHg}$ or less. There was no significant difference in the prevalence of POAG between the present study and the Tajimi Study based upon the SMR, $1.28(P>0.05$; Table 3$)$.

There were no statistical differences between non-POAG subjects and POAG patients in gender, BMI, SBP, history or presence of hypertension, blood pressure-lowering treatment, diabetic status, liver dysfunction, serum cholesterol,

Table 2 Age-specific prevalence of all glaucoma

\begin{tabular}{llll}
\hline $\begin{array}{l}\text { Age groups } \\
\text { (years) }\end{array}$ & \multicolumn{3}{l}{ Primary open-angle glaucoma patients/age population (\%, 95\% confidence interval) } \\
\cline { 2 - 4 } & Male & Female & All \\
\hline $30-39$ & $1 / 22(4.5 \%, 0.1-22.5)$ & $0 / 2 I(0.0 \%,-)$ & $1 / 43(2.3 \%, 0.1-12.3)$ \\
$40-49$ & $0 / 112(0.0 \%,-)$ & $3 / 104(2.9 \%, 0.6-8.2)$ & $3 / 216(1.4 \%, 0.3-4.0)$ \\
$50-59$ & $5 / 140(3.6 \%, 1.2-8.1)$ & $5 / 123(4.1 \%, 1.3-9.2)$ & $10 / 263(3.8 \%, 1.8-6.8)$ \\
$60-69$ & $8 / 75(10.7 \%, 4.7-19.9)$ & $3 / 58(5.2 \%, 1.1-14.4)$ & $11 / 133(8.3 \%, 4.2-14.3)$ \\
70 and older & $2 / 35(5.7 \%, 5.7-19.2)$ & $2 / 20(10.0 \%, 1.2-31.7)$ & $4 / 55(7.3 \%, 2.0-17.6)$ \\
All subjects & $16 / 384(4.2 \%, 2.4-6.7)$ & $13 / 326(4.0 \%, 2.1-6.7)$ & $29 / 710(4.1 \%, 2.8-5.8)$ \\
\hline
\end{tabular}


Table 3 Expected and observed number of POAG and standardized mortality ratio (SMR) in relation to age

\begin{tabular}{lllllll}
\hline Age (years) & $\begin{array}{l}\text { Examined } \\
\text { number }\end{array}$ & $\begin{array}{l}\text { Prevalence of POAG } \\
\text { in Tajimi }\end{array}$ & $\begin{array}{l}\text { Expected } \\
\text { number }\end{array}$ & $\begin{array}{l}\text { Observed } \\
\text { number }\end{array}$ & $\begin{array}{l}\text { SMR } \\
\text { significance }\end{array}$ \\
\hline $40-49$ & 199 & $2.0 \%$ & 3.98 & 3 & 0.75 & NS \\
$50-59$ & 242 & $2.7 \%$ & 6.53 & 8 & NS & NS \\
$60-69$ & 126 & $4.7 \%$ & 5.92 & 11 & 1.86 & NS \\
$70-$ & 54 & $7.6 \%$ & 4.10 & 4 & 0.98 & NS \\
All & 621 & $3.9 \%$ & 20.53 & 26 & 1.28 & \\
\hline
\end{tabular}

Note: NS means there is no statistically significant difference in the prevalence of POAG between the present study and the Tajimi study.

and myopia (Table 4). The mean age of POAG patients, $58.8 \pm 10.6$ years, was higher than that of non-POAG subjects $(P=0.008)$. The IOP of POAG patients, $17.2 \pm 3.3 \mathrm{mmHg}$, was higher than that of non-POAG subjects, $(P<0.001$; Table 4), while the DBP and OPP, $61.9 \pm 9.5 \mathrm{mmHg}$ and $41.1 \pm 3.0 \mathrm{mmHg}$ respectively, were lower than in non-POAG subjects ( $P=0.025$ and 0.035 , respectively).

Multivariate logistic regression analysis of possible confounders for POAG demonstrated that gender, BMI, hypertension, blood pressure-lowering treatment, diabetic status, liver dysfunction, hypercholesterolemia, and myopia were unrelated to risk (Table 5). By contrast, older age ( $\geq 75$ th percentile, 60 years old), lower DBP ( $\leq 25$ th percentile, $58 \mathrm{mmHg}$ ), higher IOP ( $\geq 75$ th percentile, $19 \mathrm{mmHg}$ ), and lower OPP ( $\leq 25$ th percentile, $34 \mathrm{mmHg}$ ) significantly improved the discrimination between POAG patients and controls (Table 6).

\section{Discussion}

In our cross-sectional examination of Japanese subjects who participated in the community health screening, the prevalence of POAG was 3.7\%. Among those with POAG, the rate of previously undiagnosed glaucoma was $89.6 \%$. After adjusting for age, the prevalence of POAG was similar to the results of the Tajimi Study of Japanese subjects. In the assessment of risk factors between non-glaucoma participants and POAG patients, we showed that lower DBP and lower OPP were significant in addition to the established risk factors of age and IOP. These findings indicate a multifactorial etiology of POAG.

The finding that low DBP is a risk factor for POAG is in agreement with a recent review, which concluded that hypotension is a stronger POAG risk factor than hypertension. ${ }^{20}$ Lower BP is associated with increased optic disk cupping and a thinner neuroretinal rim in persons without glaucoma ${ }^{21}$ thereby strengthening the possibility of a vascular link to glaucoma. ${ }^{22}$ Lower ocular perfusion pressure in our study was also significantly related to POAG risk. Similar results were found in various other epidemiologic studies in which low perfusion pressures are a consistent finding. ${ }^{6-12}$ As summarized in various reviews, ${ }^{10,23,24}$ lower perfusion pressures at the optic disk would compromise

Table 4 Differences in main characteristics between control and POAG

\begin{tabular}{llll}
\hline & Control & POAG & P value \\
\hline Systemic & & & \\
Age (years), mean \pm SD & $53.4 \pm 9.9$ & $58.8 \pm 10.6$ & 0.008 \\
Gender (male) & 348 & 15 & 0.84 \\
Body mass index $\left(\mathrm{kg} / \mathrm{m}^{2}\right)$ & $2.35 \pm 3.3$ & $23.6 \pm 3.2$ & 0.58 \\
Systolic blood pressure $(\mathrm{mmHg})$ & $112.6 \pm 19.0$ & $115.0 \pm 17.9$ & 0.51 \\
Diastolic blood pressure $(\mathrm{mmHg})$ & $68.2 \pm 12.9$ & $61.9 \pm 9.5$ & 0.025 \\
Hypertension & 125 & 5 & 0.98 \\
Blood pressure-lowering treatment & 120 & 5 & 0.99 \\
Diabetic status & 54 & 2 & 0.97 \\
Liver dysfunction & 94 & 4 & 0.99 \\
Cholesterol (mg/dL) & $211.1 \pm 33.2$ & $211.0 \pm 31.2$ & 0.90 \\
Ocular & & & \\
Intraocular pressure $(\mathrm{mmHg})$ & $15.0 \pm 2.9$ & $17.2 \pm 3.3$ & \\
Ocular perfusion pressure $(\mathrm{mmHg})$ & $43.2 \pm 5.0$ & $41.1 \pm 3.0$ & \\
Myopia & 326 & 11 & 0.035 \\
\hline
\end{tabular}

Abbreviations: POAG, primary open-angle glaucoma; SD, standard deviation. 
Table 5 Adjusted odds ratios of possible confounders for POAG

\begin{tabular}{|c|c|c|}
\hline & $\begin{array}{l}\text { Adjusted odds } \\
\text { ratio* }\end{array}$ & $\begin{array}{l}95 \% \text { confidence } \\
\text { interval }\end{array}$ \\
\hline \multicolumn{3}{|l|}{ Gender } \\
\hline Male & 1.00 & Reference \\
\hline Female & 1.69 & $0.76-3.75$ \\
\hline \multicolumn{3}{|l|}{ Body mass index } \\
\hline$<25$ & 1.00 & Reference \\
\hline$\geq 25$ & 1.73 & $0.76-3.99$ \\
\hline \multicolumn{3}{|l|}{ Hypertension } \\
\hline No & 1.00 & Reference \\
\hline Yes & 1.07 & $0.4 I-2.78$ \\
\hline \multicolumn{3}{|c|}{ Blood pressure-lowering treatment } \\
\hline No & 1.00 & Reference \\
\hline Yes & 9.06 & $0.10-14.8$ \\
\hline \multicolumn{3}{|l|}{ Diabetic status } \\
\hline No & 1.00 & Reference \\
\hline Yes & 1.58 & $0.35-7.14$ \\
\hline \multicolumn{3}{|l|}{ Liver dysfunction } \\
\hline No & 1.00 & Reference \\
\hline Yes & 1.01 & $0.30-3.82$ \\
\hline \multicolumn{3}{|l|}{ Hypercholesterolemia } \\
\hline $\mathrm{Chr}<220 \mathrm{mg} / \mathrm{dL}$ & 1.00 & Reference \\
\hline $\mathrm{Chr} \geq 220 \mathrm{mg} / \mathrm{dL}$ & 1.13 & $0.5 \mathrm{I}-2.55$ \\
\hline \multicolumn{3}{|l|}{ Myopia } \\
\hline No & 1.00 & Reference \\
\hline Yes & 1.23 & $0.89-1.45$ \\
\hline
\end{tabular}

Note: *Based on multivariate logistic regression analysis adjusted for age, gender, diastolic blood pressure. intraocular pressure, and ocular perfusion pressure.

ocular blood flow and thus lead to glaucomatous damage. In this context, we also examined the effects of blood pressurelowering treatment, but found no associations with POAG, supporting the conclusion that lower perfusion pressures are the important risk factor. The other demographic factors investigated in this study, gender, BMI, SBP, a history or presence of hypertension, diabetic status, liver dysfunction, serum cholesterol, and myopia, were not associated with POAG in our analyses. Our result concerning myopia is inconsistent with a previous report in Japanese. ${ }^{25}$
There are several limitations in the present analyses. First is the small sample size, which resulted in estimates of association with relatively broad confidence intervals. Second, this study was not a population-based survey because the subjects who participated may have been highly interested in glaucoma. Thus to a degree, they were self-selected to participate in the screening, and may not have been representative of the general population. This could have introduced a selection bias resulting in an overestimation of the prevalence of POAG. Third, we did not perform definitive examinations of participants whose eyes appeared normal in the initial screening examination. Therefore, some subjects with glaucoma may have been overlooked, resulting in an underestimation of the prevalence of POAG. In the present study, we excluded tilted disks from analysis to have precise diagnosis. However, there is a potential problem in excluding such eyes, as myopia is thought to be a risk factor for glaucoma: we could be underestimating the prevalence of glaucoma. ${ }^{26}$ Finally, there were several factors not included in the present analysis but reported to be associated with the development of POAG, such as systemic medications, ${ }^{9,27}$ other ocular diseases, ${ }^{9}$ and computer use. ${ }^{28}$ Family history of glaucoma is associated with the development of the condition; ${ }^{29-32}$ however, we obtained only limited information regarding family histories of glaucoma.

Because of the irreversible nature of glaucoma, early disease detection through screening will likely provide a substantial benefit by reducing blindness. However, the value of glaucoma screening has been a topic of debate for many years. Prior evaluations of screening effectiveness have concluded that there is insufficient economic evidence to recommend screening for POAG.$^{33}$ Since screening is sensitive to the prevalence of glaucoma in the study population, ${ }^{34}$ identifying and targeting high-risk patients should improve the program's cost-effectiveness. The present study has proposed potential risk factors for POAG. These include

Table 6 Odds ratios of risk factors for POAG

\begin{tabular}{|c|c|c|c|}
\hline & $\begin{array}{l}\text { Odds ratio } \\
\text { ( } 95 \% \text { confidence limit) }\end{array}$ & $\begin{array}{l}\text { Adjusted odds ratio }^{2} \\
\text { ( } 95 \% \text { confidence limit) }\end{array}$ & $\begin{array}{l}\text { Adjusted odds ratio }{ }^{3} \\
\text { ( } 95 \% \text { confidence limit) }\end{array}$ \\
\hline Age $\geq 60$ years & $2.56(I .22-5.4 I)$ & $3.49(1.41-8.62)$ & $3.54(\mathrm{I} .42-8.8 \mathrm{I})$ \\
\hline $\mathrm{DBP} \leq 58 \mathrm{mmHg}$ & $2.08(1.21-5.45)$ & $2.11(1.69-6.67)$ & $2.50(1.11-10.05)$ \\
\hline $\mathrm{IOP} \geq 19 \mathrm{mmHg}$ & $4.19(1.91-9.16)$ & $4.12(1.35-12.56)$ & $3.38(1.02-11.18)$ \\
\hline $\mathrm{OPP} \leq 34 \mathrm{mmHg}$ & $5.44(1.11-8.26)$ & $5.78(1.21-7.92)$ & $5.54(1.12-6.18)$ \\
\hline
\end{tabular}

Notes: 'Based on Yates chi-square test; ' ${ }^{2}$ based on multivariate logistic regression analysis adjusted for age, gender, diastolic blood pressure, intraocular pressure, and ocular perfusion pressure; ${ }^{3}$ based on multivariate logistic regression analysis adjusted for age, gender, BMl, diastolic blood pressure, hypertension, hypercholesterolemia, intraocular pressure, and ocular perfusion pressure.

Abbreviations: DBP, diastolic blood pressure; IOP, intraocular pressure; OPP, ocular perfusion pressure. 
older age, higher IOP, lower diastolic pressure, and lower ocular perfusion pressure. These risk factors may provide effective guidelines for targeting community glaucoma screening to the highest risk populations.

\section{Acknowledgment}

The authors would like to thank Professor Katsuyuki Murata, Department of Environmental Health Science, Akita University School of Medicine, for his teaching and help in the statistical analysis.

\section{Disclosure}

This study was supported by grant 30000020 from the National Health and Labor Science Research (Tokyo, Japan) to Professor Takeshi Yoshitomi.

\section{References}

1. Iwase A, Suzuki Y, Araie M, et al; Tajimi Study Group and Japan Glaucoma Society. The prevalence of primary open-angle glaucoma in Japanese: the Tajimi Study. Ophthalmology. 2001;111(9):641-1648.

2. Kwon YH, Caprioli J. Primary open angle glaucoma. In: Tasman W, Jaeger EA, editors. Duane's Clinical Ophthalmology. Philadelphia, PA: JB Lippincott; 1999:1-30.

3. Alward WLM (2000): Open angle glaucomas. In: Alward WLM, editor. Glaucoma: the Requisites in Ophthalmology. St Louis, MO: Mosby; 2000:128-140.

4. Kwon YH, Fingert JH, Kuehn MH, Alward WL. Primary open-angle glaucoma. N Engl J Med. 2009;360(11):1113-1124.

5. Williams TD. Diseases of the optic nerve, tracts, and visual cortex: an annual review of the ophthalmic literature. Am J Optom Physiol Opt. 1978;55(9):652-659.

6. Tielsch JM, Katz J, Sommer A, Quigley HA, Javitt JC. Hypertension, perfusion pressure, and primary open-angle glaucoma: a populationbased assessment. Arch Ophthalmol. 1995;113(2):216-221.

7. Leske MC, Connell AM, Wu SY, Hyman LG, Schachat AP. Risk factors for open-angle glaucoma: the Barbados Eye Study. Arch Ophthalmol. 1995;113(7):918-924.

8. Leske MC, Warheit-Roberts L, Wu SY. Open-angle glaucoma and ocular hypertension: the Long Island Glaucoma Case-Control Study. Ophthalmic Epidemiol. 1996;3(2):85-96.

9. Bonomi L, Marchini G, Marraffa M, Bernardi P, Morbio R, Varotto A. Vascular risk factors for primary open angle glaucoma: the EgnaNeumarkt Study. Ophthalmology. 2000;107(7):1287-1293.

10. Flammer J, Orgul S, Costa VP, et al. The impact of ocular blood flow in glaucoma. Prog Retin Eye Res. 2002;21(4):359-393.

11. Leske MC, Wu SY, Nemesure B, Hennis A. Incident open-angle glaucoma and blood pressure. Arch Ophthalmol. 2002;120(7):954-959.

12. Leske MC, Wu SY, Hennis A, Honkanen R, Nemesure B, BESs Study Group. Risk factors for incident open-angle glaucoma: The Barbados Eye Study. Ophthalmology. 2008;115(1):85-93.

13. Tokunaga T, Kashiwagi K, Tsumura T, Taguchi K, Tsukahara S. Association between nocturnal blood pressure reduction and progression of visual field defect in patients with primary open-angle glaucoma or normal-tension glaucoma. Jpn J Ophthalmol. 2001;48(4):380-385.

14. Wang S, Xu L, Jonas JB, et al. Major eye diseases and risk factors associated with systemic hypertension in an adult Chinese population: the Beijing Eye Study. Ophthalmology. 2009;116(12):2373-2380.
15. Zheng Y, Wong T, Mitchell P, Friedman DS, He M, Aung T. Distribution of ocular perfusion pressure and its relationship with open angle glaucoma: The Singapore Malay Eye Study. Invest Ophthalmol Vis Sci. 2010;51(7):3399-3404.

16. Yamamoto T, Iwase A, Araie M, et al; Tajimi Study Group, Japan Glaucoma Society. The Tajimi study report 2: prevalence of primary angle closure and secondary glaucoma in a Japanese population. Ophthalmology. 2005;112(10):1661-1669.

17. Tanaka Y, Atsumi Y, Matsuoka K, et al. Usefulness of stable HbAlc for supportive marker to diagnose diabetes mellitus in Japanese subjects. Diab Res Clin Pract. 2001;53(1):41-45.

18. Whitworth JA, World Health Organization, International Society of Hypertension Writing Group. 2003 World Health Organization (WHO)/ International Society of Hypertension (ISH) statement on management of hypertension: guidelines and recommendations. J Hypertens. 2003;21(11):1983-1992.

19. Kotani K, Katase H, Saiga K, Sakane N. Japanese guidelines-based management of lipid levels in a hypercholesterolemia education class. Arch Med Res. 2006;37(1):175-177.

20. Pache M, Flammer J. A sick eye in a sick body? Systemic findings in patients with primary open-angle glaucoma. Surv Ophthalmol. 2006;51(3):179-212.

21. Topouzis F, Coleman AL, Harris A, et al. Association of blood pressure status with the optic disk structure in non-glaucoma subjects: the Thessaloniki Eye Study. Am J Ophthalmol. 2006;142(1):60-67.

22. Jonas JB. Association of blood pressure status with the optic disk structure. Am J Ophthalmol. 2006;142(1):144-145.

23. Harris A, Rechtman E, Siesky B, Jonescu-Cuypers C, McCranor L, Garzozi HJ. The role of optic nerve blood flow in the pathogenesis of glaucoma. Ophthalmol Clin North Am. 2005;18(3):345-353.

24. Grieshaber MC, Flammer J. Blood flow in glaucoma. Curr Opin Ophthalmol. 2005;16(2):79-83.

25. Suzuki Y, Iwase A, Araie M, et al; Tajimi Study Group, Japan Glaucoma Society. Risk factors for open-angle glaucoma in a Japanese population: The Tajimi Study. Ophthalmology. 2006;113(9):1613-1617.

26. Aung T, Foster PJ, Seah SK, et al. Automated static perimetry: the influence of myopia and its method of correction. Ophthalmology. 2001;108(2):290-295.

27. Müskens RP, de Voogd S, Wolfs RC, et al. Systemic antihypertensive medication and incident open-angle glaucoma. Ophthalmology. 2007;114(12):2221-2226

28. Tatemichi M, Nakano T, Tanaka K, et al. Possible association between heavy computer users and glaucomatous visual field abnormalities; a cross sectional study in Japanese workers. J Epidemiol Community Health. 2004;58(12):1021-1027.

29. Tielsch JM, Katz J, Sommer A, Quigley HA, Javitt JC. Family history and risk of primary open-angle glaucoma: the Baltimore Eye Survey. Arch Ophthalmol. 1994;112(1):69-73.

30. Wilson MR, Hertzmark E, Walker AM, Childs-Shaw K, Epstein DL. A case-control study of risk factors in open angle glaucoma. Arch Ophthalmol. 1987;105(8):1066-1071.

31. Wolfs RC, Klaver CC, Ramrattan RS, van Duijn CM, Hofman A, de Jong PT. Genetic risk of primary open-angle glaucoma: populationbased familial aggregation study. Arch Ophthalmol. 1998;116(12): $1640-1645$.

32. Nemesure B, He Q, Mendell N, et al; Barbados Family Study Group. Inheritance of open-angle glaucoma in the Barbados Family Study. Am J Med Genet. 2001;103(1):36-43.

33. Hernandez R, Rabindranath K, Fraser C, Vale L, Blanco AA, Burr JM; OAG Screening Project Group. Screening for open angle glaucoma: systemic review of cost-effectiveness studies. J Glaucoma. 2008;17(3):159-168.

34. Boivin J, McGregor M, Archer C. Cost effectiveness of screening for primary open angle glaucoma. J Med Screen. 1996;3(3):154-163. 
Clinical Ophthalmology

\section{Publish your work in this journal}

Clinical Ophthalmology is an international, peer-reviewed journal covering all subspecialties within ophthalmology. Key topics include: Optometry; Visual science; Pharmacology and drug therapy in eye diseases; Basic Sciences; Primary and Secondary eye care; Patien Safety and Quality of Care Improvements. This journal is indexed on

PubMed Central and CAS, and is the official journal of The Society of Clinical Ophthalmology (SCO). The manuscript management system is completely online and includes a very quick and fair peer-review system, which is all easy to use. Visit http://www.dovepress.com/ testimonials.php to read real quotes from published authors. 